\title{
Investigation and Optimization of Temperature and Force Behavior in High-Speed Bone Drilling
}

\author{
Mohsen Sarparast* and Tohid Jahangirpoor \\ Department of Mechanical Engineering, Iran
}

*Corresponding author: Mohsen Sarparast, Department of Mechanical Engineering, K.N. Toosi University of Technology, Tehran, Iran

\begin{abstract}
Nowadays, Implantation is one of the inevitable methods of internal fixation in orthopedic surgery and dentistry. In many cases, bone drilling causes an increase in bone temperature (more than $47^{\circ} \mathrm{C}$ ) and this phenomenon leads to thermal osteonecrosis. In addition, excessive thrust force during drilling process increases probability of drill bit fracture. In this study, it has been shown that high-speed bone drilling is an appropriate method for descending process temperature and force simultaneously. Also, rotational speed, feed rate and tool diameter are the most important factors of the process. In high-speed bone drilling, contrary to conventional drilling process, high rotational speed results in a decrease in process temperature and force. Therefore, in robotic surgery high-speed bone drilling is considerably suitable method for implantation
\end{abstract}

Keywords: Orthopedic surgery; high-speed bone drilling; design of experiments; force; temperature; thermal osteonecrosis

\section{Introduction}

Implantation is one of the prominent processes in medical surgery. Most of the operations in orthopedic surgery and dentistry need drilling for fixation of implant in the bone. Therefore, during drilling process owing to low thermal conductivity of bone tissue (approximately $0.38-2.3 \mathrm{~J} / \mathrm{mK}$ ), the temperature in drilling zone increases significantly (higher than $47^{\circ} \mathrm{C}$ ) [1]. This phenomenon leads to cell death which is called thermal osteonecrosis. In fact, this decreases in material stiffness, causes the fitting screws to wobble in the bone and increases the period of treatment $[2,3]$. In addition, large amount of thrust force during conventional bone drilling increases the probability of drill bit fracture. Therefore, reducing drilling temperature and force is a critical objective and has significant role in robotic surgery.

\section{Materials and methods}

\section{Statistical analysis}

In this study, in order to determine the number of experiments and considering the interactions between process parameters, response surface method was used. By using this method, the number of tests needed to reach a high accuracy response was determined [4]. The general form of the equation which includes the main effect of the factors and effective interactions is presented in equation (1) [5].

$$
y=\beta_{0}+\sum_{i=1}^{K} \beta_{i} x_{i}+\sum_{i=1}^{K} \beta_{i i} x_{i}^{2}+\sum_{i} \sum_{j} \beta_{i j} x_{i} x_{j}+\varepsilon
$$

Where

$\beta$ is the regression coefficient matrix,

$\mathrm{x}_{\mathrm{i}}$ is the experiment input factor,

$x_{i}^{2}$ square of experiment input factor,

$\mathrm{x}_{\mathrm{i}} \mathrm{x}_{\mathrm{j}}$ are the second -order interactions of the input

\section{Experimental setup}

Since bovine cortical bone's physical and mechanical properties are very similar to human bones [6,7], a piece of fresh bovine bone was used for experiments. A high-speed conduction motor (model Arel TIP: ARFM 1Y-M3 with a maximum of 18000RPM), K-type thermocouple, load cell (model Zemic L6E3 with the capacity of $500 \mathrm{~N}$ and resolution of 0.01 ) and HSS drill bits were also used in order to conduct experiments [8] (Figure 1). 


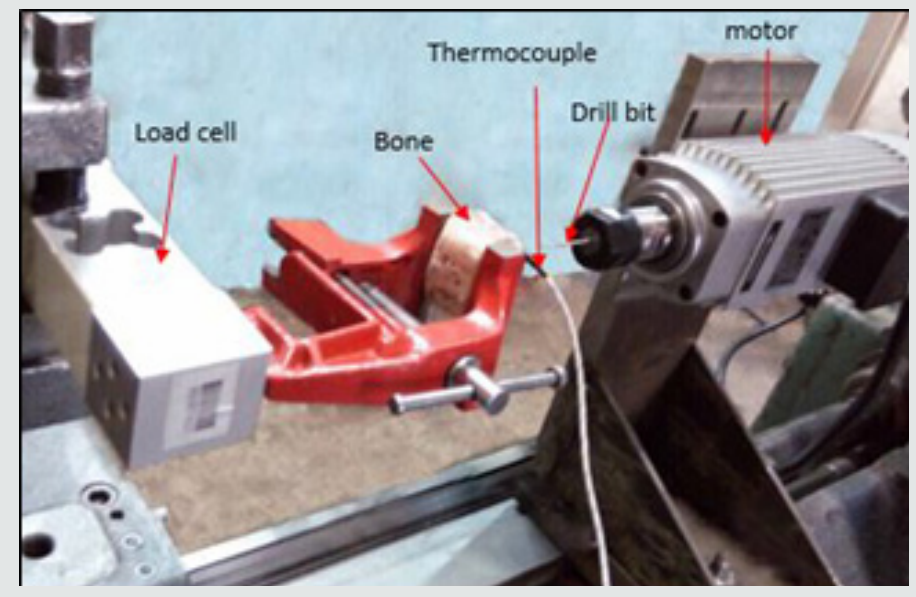

Figure 1: The experiment set up and thermocouple position [8].

\section{Results and Discussion}

In high-speed bone drilling process, high rotational velocity contributor to growing the friction between the drill bit and the hole wall and it result is rising bone temperature. In addition, in this process, there is an inverse relationship between the tool feed rate and bone temperature (bone temperature has an insignificant fall with increasing feed rate). As a result, there is no limitations when using high feed rates. Using low diameter drill bit decreases the friction in drilling zone which causes bone temperature to fall and reduces risk of thermal necrosis. Since in this process the chip is in powder form and the existence speed is high, in high-speed bone drilling the drill force is considerably lower than that of ordinary drilling process.

\section{Conclusion}

There is an optimum point in process parameters when the rotational speed, feed rate and tool diameter are 11778rpm, $50 \mathrm{~mm} / \mathrm{min}$ and $2 \mathrm{~mm}$, respectively. In this case the values of temperature and force are $33.4{ }^{\circ} \mathrm{C}$ and $15.85 \mathrm{~N}$. Therefore, according to low thermal damage and thrust force, high-speed bone drilling is preferred to conventional drilling. Also, findings in this research can help surgeons to select proper set up parameters in order to reduce process temperature and force.

\section{References}

1. Hillery MT, Shuaib I (1999) Temperature effects in the drilling of human and bovine bone. Journal of Materials Processing Technology 92-93: 302-308.

2. Sui J, Naohiko S, Kentaro I, Kanako H, Mamoru M (2014) Mechanistic modeling of bone-drilling process with experimental validation. Journal of Materials Processing Technology 214(4): 1018-1026.

3. Bachus KN, Rondina MT, Hutchinson DT (2000) The effects of drilling force on cortical temperatures and their duration: an in vitro study. Med Eng Phys 22(10): 685-691.

4. Myers RH, Montgomery DC, Vining GG, Borror CM, Kowalski SM (2004) Response surface methodology: a retrospective and literature survey. Journal of Quality Technology 36(1): 53-77.

5. Wang W, Shi Y, Yang N, Yuan X (2014) Experimental analysis of drilling process in cortical bone. Med Eng Phys 36(2): 261-266.

6. Singh G, Jain V, Gupta D, Ghai A (2016) Optimization of process parameters for drilled hole quality characteristics during cortical bone drilling using Taguchi method. J Mech Behav Biomed Mater 62: 355-365.

7. Vashishth DK, Tanner KE, Bonfield W (2000) Contribution, development and morphology of microcracking in cortical bone during crack propagation. J Biomech 33(9): 1169-1174.

8. Sarparast M, Ghoreishi M, Jahangirpoor T, Tahmasbi V (2019) Modelling and optimisation of temperature and force behaviour in high-speed bone drilling. Biotechnology \& Biotechnological Equipment 33(1): 1616-1625.

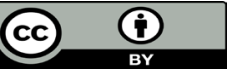

This work is licensed under Creative Commons Attribution 4.0 License

To Submit Your Article Click Here: Submit Article

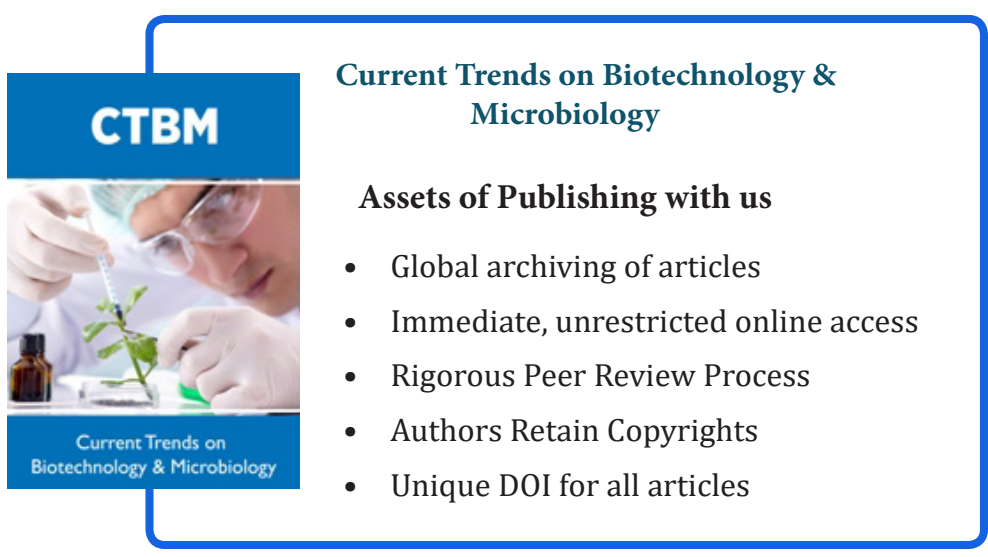

